\title{
Microstructure and Mechanical Properties of Cement Mortar Containing Phase Change Materials
}

\author{
Hyun-Do Yun ${ }^{1}$, Jong-Won Lee $\left.{ }^{2}{ }^{(}\right)$, Young-Il Jang ${ }^{2}{ }^{(}$, Seok-Joon Jang ${ }^{3}$ and Wonchang Choi ${ }^{4, *}$ (i) \\ 1 Department of Architectural Engineering, Chungnam National University, \\ Daejeon 34134, Korea; wiseroad@cnu.ac.kr \\ 2 Department of Convergence Systems Engineering, Chungnam National University, \\ Daejeon 34134, Korea; asca28@cnu.ac.kr (J.-W.L.); jang1001@cnu.ac.kr (Y.-I.J.) \\ 3 Research Institute for Infrastructure Performance, Korea Infrastructure Safety Corporation, \\ Gyeongsangnam 52856, Korea; jang@cnu.ac.kr \\ 4 Department of Architectural Engineering, Gachon University, Gyunggi 13120, Korea \\ * Correspondence: wchoi@gachon.ac.kr; Tel.: +82-31-750-5335
}

Received: 1 February 2019; Accepted: 27 February 2019; Published: 6 March 2019

\begin{abstract}
This paper presents an investigation of the characterization of cement mortar containing phase change materials (PCMs) in order to control the development of hydration heat. The study examined microstructural characteristics and properties of cement mortar with PCMs such as flow, compressive strength, and flexural strength. This research involved two types of PCM and up to $15 \%$ cement added to cement mortar mixtures. The two types of PCM used in this study are PCM with barium (PCM-Ba) and PCM with strontium (PCM-Sr). The experimental results indicate that both the incremental temperature rise and the maximum temperature release time of PCM up to $5 \%$ addition are delayed. Both PCM-Ba and PCM-Sr are effective in reducing the development of hydration heat. The microstructural analysis results show that the crystalloid content of cement mortar without PCMs is about 3\% more from cement mortar with PCMs, regardless of the type of PCMs used, and that no significant difference is evident in the formation of crystals between cement mortar with and without PCMs.
\end{abstract}

Keywords: phase change material (PCM); hydration heat; mechanical properties; microstructure; crystalloid

\section{Introduction}

The temperature control of mass concrete is an important concern for large-scale construction. High thermal stress that was developed by the rapid escalation of hydration heat in mass concrete can cause unpredictable cracks in the concrete structure. Several methods can be employed to control hydration heat, including the use of moderate heat cement, fly ash, blast furnace slag cement, and admixtures [1-3] as well as precooling, pipe cooling, and block placement associated with construction methods [4-6]. However, these methods involve some challenges in terms of constructability and economic efficiency [7].

The use of phase change material (PCM) is an effective way to control the hydration heat of mass concrete. PCM absorbs and emits heat during the transition phases from solid to liquid and from liquid to solid at the transition temperature boundary [8]. The various kinds of PCM can be divided into organic PCM, inorganic PCM, and eutectic PCM, depending on the melting point and latent heat from melting $[9,10]$. In construction, PCM can serve to control the rapid temperature rise of heat-radiating material through latent heat storage [11]. Therefore, researchers have attempted to control the temperature changes of concrete by using PCM to improve both the heat insulation performance and the freeze-thaw resistance of concrete elements [12,13]. 
In order to predict the cracking in mass concrete that is due to a rise in temperature, the strength and hydration characteristics of the concrete need to be evaluated at the initial stages of the concrete placement, which occurs rapidly with a rise in temperature. However, as yet, researchers have not evaluated the hydration characteristics of cement mortar according to changes in initial strength of concrete that are due to the inclusion of PCM as an admixture. Two types of PCM-barium-based (PCM-Ba) and strontium-based (PCM-Sr) — were employed to investigate the microstructure and mechanical properties of cement mortar mixed with these two types of PCM.

\section{Materials and Experimental Method}

The materials used in this study are conventional Type I Portland cement, Class F fly ash, and blast furnace slag. The specific gravity and fineness of Type I Portland cement are $3.15 \mathrm{~g} / \mathrm{cm}^{3}$ and $3300 \mathrm{~cm}^{2} / \mathrm{g}$, respectively. In accordance with related previous research results (Kim and Lee 2009), we used the phase change temperature of $78.0^{\circ} \mathrm{C}$ and latent heat of $266 \mathrm{~J} / \mathrm{g}$ for barium hydroxide $\left(\mathrm{Ba}(\mathrm{OH})_{2} \cdot 8 \mathrm{H}_{2} \mathrm{O}\right)$ and the phase change temperature of $88.0^{\circ} \mathrm{C}$ and latent heat of $343 \mathrm{~J} / \mathrm{g}$ for strontium hydroxide $\left(\mathrm{Sr}(\mathrm{OH})_{2} \cdot 8 \mathrm{H}_{2} \mathrm{O}\right)$.

Table 1 shows the mix proportions for each mix design. We adopted a water-to-cement ratio of 0.5 and set the mixing percentage of the PCM-Ba and PCM-Sr from $0 \%$ to $15 \%$, respectively, relative to the weight of the cement. In order to evaluate the effects of adding the two types of PCM to the cement mixture, we did not use any chemical or mineral admixture that could affect the initial hydration reaction. Also, cement with the same production date was used in this study.

Table 1. Mixing proportions.

\begin{tabular}{|c|c|c|c|c|c|c|c|c|c|c|}
\hline \multirow{2}{*}{ Mix No. } & \multirow{2}{*}{$\mathrm{W} / \mathrm{C}$} & \multirow{2}{*}{ Cement (g) } & \multirow{2}{*}{ Water (g) } & \multirow{2}{*}{ Sand (g) } & \multicolumn{5}{|c|}{ PCM (g) } & \multirow{2}{*}{ Test Item } \\
\hline & & & & & $0 \%$ & $3 \%$ & $5 \%$ & $10 \%$ & $15 \%$ & \\
\hline OPC & \multirow{3}{*}{0.5} & \multirow{3}{*}{450} & \multirow{3}{*}{255} & \multirow{3}{*}{1350} & - & - & - & - & - & XRD \\
\hline PCM-Ba & & & & & - & 13.5 & 22.5 & 45 & 67.5 & Flow test \\
\hline $\mathrm{PCM}-\mathrm{Sr}$ & & & & & - & 13.5 & 22.5 & 45 & 67.5 & Compressive test \\
\hline PCM-Ba & \multirow[t]{2}{*}{0.5} & \multirow[t]{2}{*}{2800} & \multirow[t]{2}{*}{1400} & \multirow[t]{2}{*}{6860} & - & 84 & 140 & 280 & 420 & \multirow[t]{2}{*}{ Semi-adiabatic temperature rise test } \\
\hline PCM-Sr & & & & & - & 84 & 140 & 280 & 420 & \\
\hline
\end{tabular}

Note: OPC is ordinary Portland cement; W/B is water-to-binder ratio; XRD is X-ray diffraction; SEM is scanning electron microscopy.

The mortar flow in accordance with American Society for Testing and Materials (ASTM) Standards: C 1437 [14] was immediately measured after mixing to evaluate the workability of the mix. In order to evaluate the hydration characteristics, simple adiabatic temperature rise tests were conducted. Three bending strength specimens were prepared to evaluate the compressive strength and flexural strength of the specimens and six compressive tests were conducted at $1,3,7,28$, and 91 days.

X-ray diffraction (XRD) analysis was carried out with the samples by crushing or finely grinding the specimen. The cement mortar-related materials were qualitatively investigated using only peak values. The crystalline and amorphous materials were analyzed and evaluated for their contents.

Scanning electron microscopy (SEM) has been carried out to identify the reaction products of the cement admixture that contained the PCMs. The cross-section of the specimens was less than $15 \mathrm{~mm} \times 15 \mathrm{~mm}$ and less than $1 \mathrm{~mm}$ in height. The specimens were immersed in acetone to prevent contact with air and change in the mortar. The surface of the sample was coated with platinum $(\mathrm{Pt})$ to a thickness of about $200 \AA$. Because gas and moisture were present inside the sample, a vacuum process was carried out for about six hours.

Figure 1 shows the methods we used to evaluate the mechanical properties, i.e., the flexural and compressive strength of the cement mortar specimens that contained PCM. The cement mortar flow was immediately measured after mixing to evaluate the change in workability according to the 
PCM mixing ratio and was measured again after 15 strokes. The tests were in accordance with KS L ISO 679 [15]. Three specimens, $40 \mathrm{~mm} \times 40 \mathrm{~mm} \times 160 \mathrm{~mm}$, for each mixture were prepared and the flexural strength was measured by three-point bending with a span distance of $100 \mathrm{~mm}$. After the flexural tests, we used the half-broken samples for the compressive strength tests.

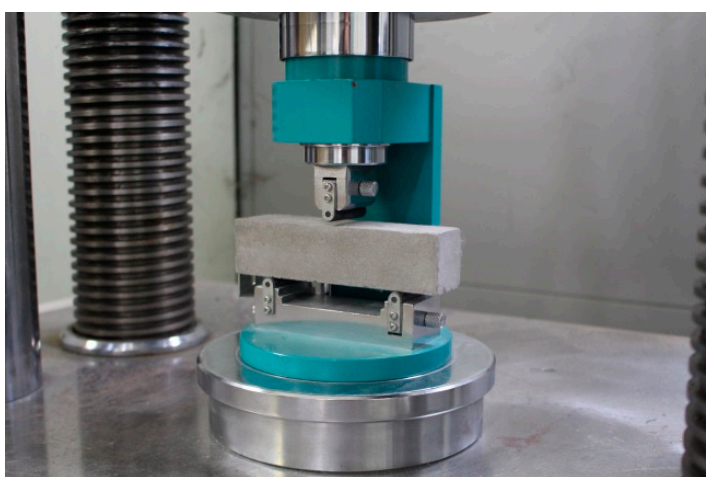

(a)

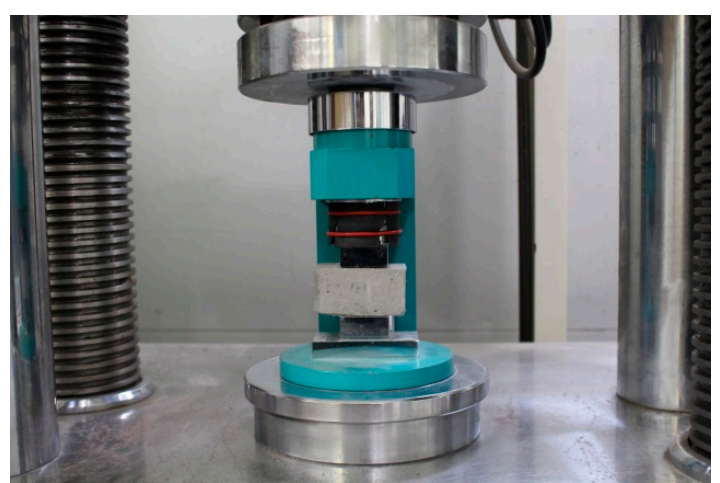

(b)

Figure 1. Set-up for mechanical properties testing-(a) flexural strength; (b) compressive strength.

In order to evaluate the hydration characteristics, we performed simple adiabatic temperature rise tests. Figure 2 shows the set-up for the semi-adiabatic temperature rise tests in which the adiabatic temperature is increased in order to evaluate the effect of the PCM content on the hydration heat properties of the cement mortar. For this test, a cube-shaped mold with heat-insulating material that had an inner dimension of $100 \mathrm{~mm} \times 100 \mathrm{~mm} \times 100 \mathrm{~mm}$ were fabricated and the thickness of the heat-insulating material was set to $100 \mathrm{~mm}$. Then, the temperature at the center of the specimen and the outside temperature were measured simultaneously using a thermocouple. The temperature was maintained to within $20^{\circ} \mathrm{C}$ to minimize the effect of the initial casting temperature on the simple adiabatic test. All the materials were kept sealed in a thermo-hygrostat for $24 \mathrm{~h}$ before pouring.
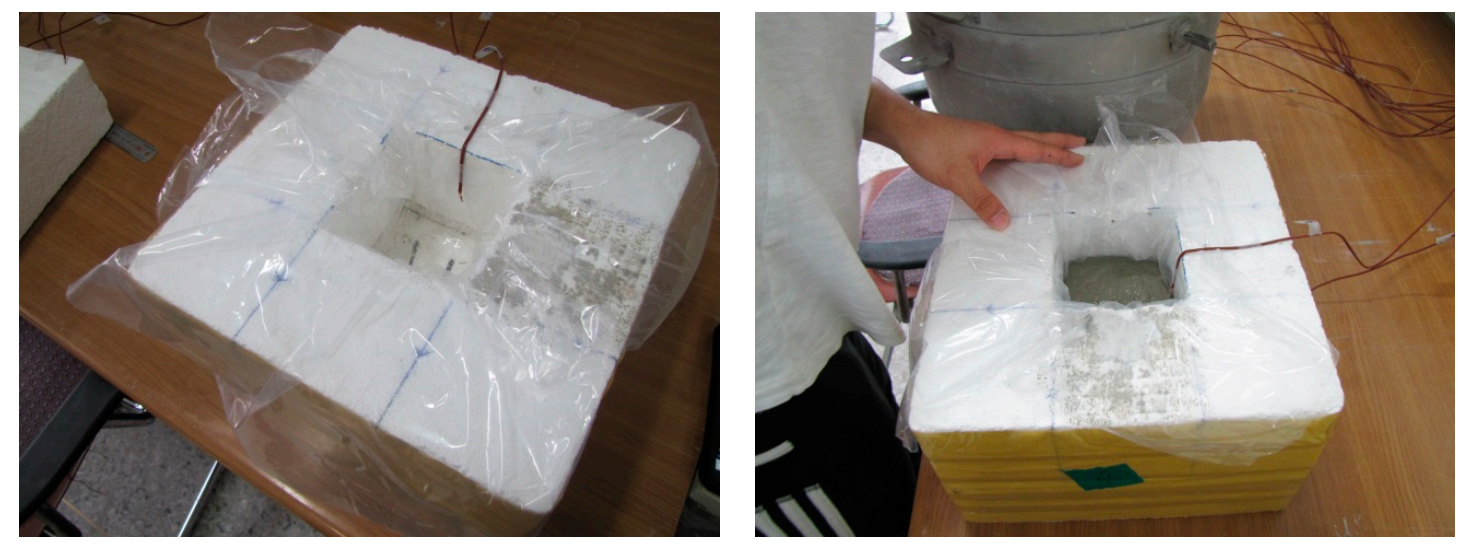

Figure 2. Set-up for semi-adiabatic temperature rise testing.

\section{Results and Discussion}

\subsection{X-ray Diffraction Analysis}

Figures 3 and 4 present the results of the XRD analysis to show the crystalline formation and kinds of crystalline materials according to the age of the cement mortar specimens that contain PCM. Figure 3 shows that the crystalloid contents of the PCM mixed paste at 3 days of aging are about $64 \% \sim 67 \%$, which is $3 \% \sim 6 \%$ lower than that of the ordinary Portland cement (OPC), but the crystalloid contents at 28 days of aging are an increase of about $73 \% \sim 76 \%$. There is no significant difference compared to OPC specimens. 


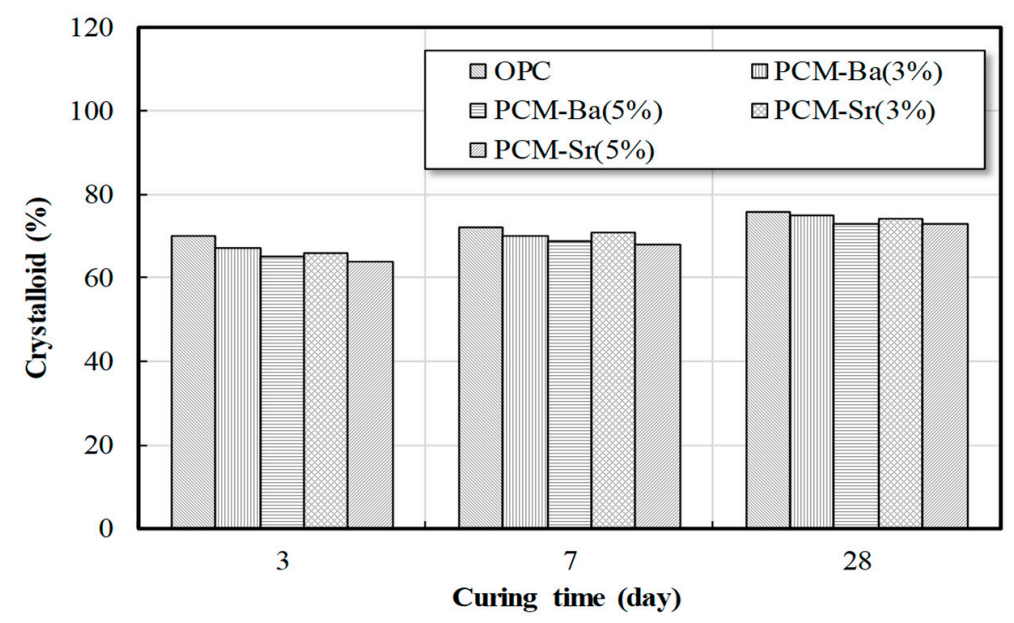

Figure 3. Crystalloid contents of cement mortar.

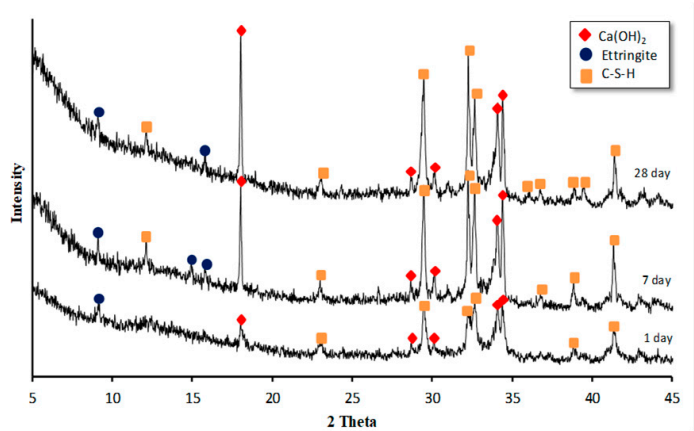

(a)

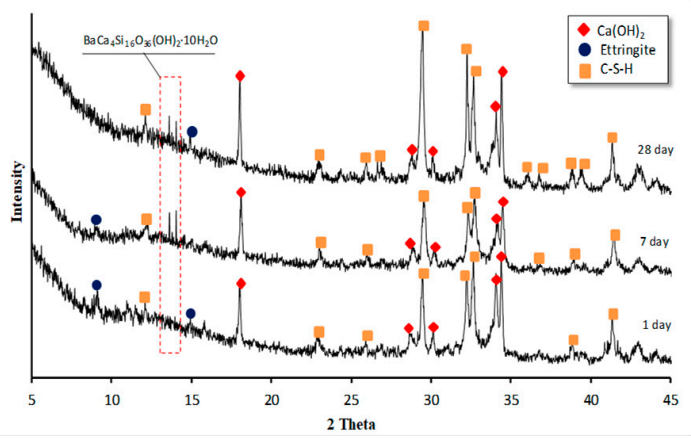

(b)

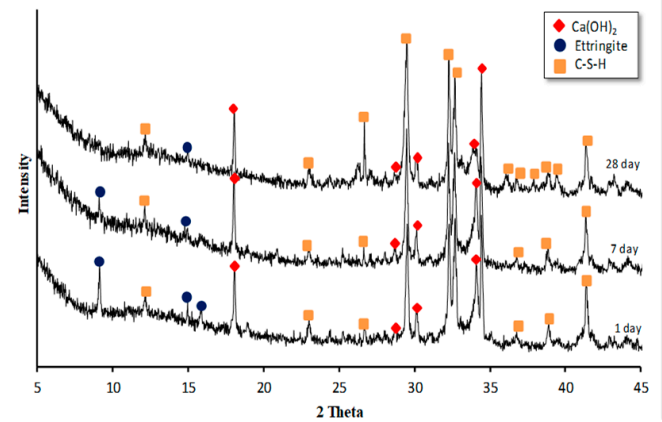

(d)

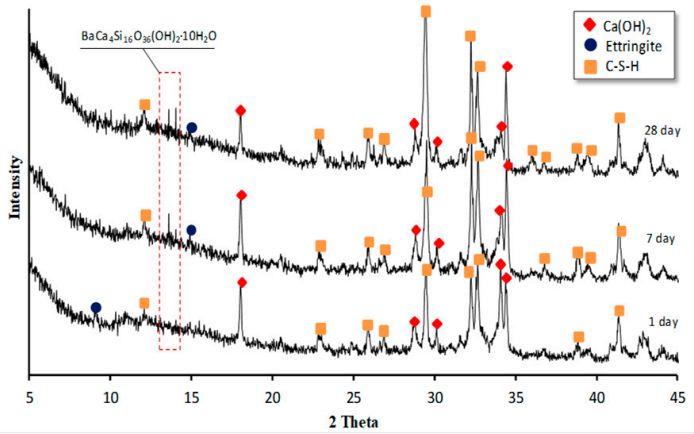

(c)

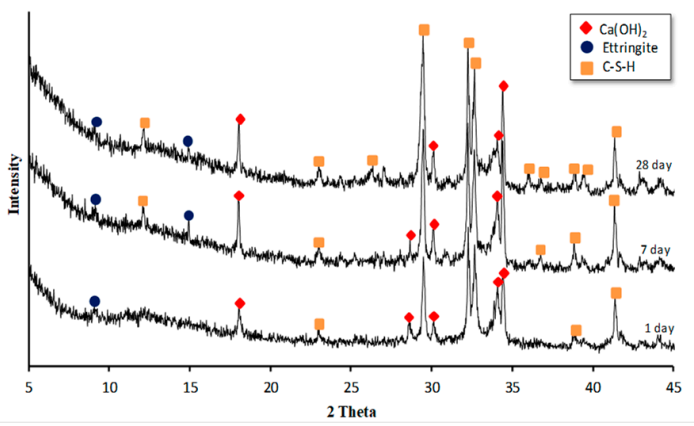

(e)

Figure 4. X-ray diffraction analysis results for each specimen for number of days of curing-(a) cement mortar; (b) phase change material with barium (PCM-Ba) (3\%) mortar; (c) PCM-Ba (5\%) mortar; (d) phase change material with strontium (PCM-Sr) (3\%) mortar; and (e) PCM-Sr (5\%) mortar. 
Also, Figure 4 indicates that no significant difference is evident in the crystal formation between the cement mortar specimens with and without PCM. Ettringite and $\mathrm{Ca}(\mathrm{OH})_{2}$ and C-S-H gels were formed in all the formulations, and the amount of the compound production is shown to increase gradually with aging. In particular, the peak of the ettringite is lower with the addition of the PCM, but the $\mathrm{Ca}(\mathrm{OH})_{2}$ peak is more than two times higher than that of the OPC. This finding indicates an increase in the $\mathrm{OH}$ ion due to the $\mathrm{Ba}$ and $\mathrm{Sr}$ reaction with the $\mathrm{CaO}$ components of the cement. Unlike the OPC mortar, which is a complex hydrate form of polycrystalline isotropy, the mortar crystals that contain PCM are polycrystalline anisotropic.

However, in the mortar mixed with $\mathrm{Ba}$, macdonaldite with $\mathrm{BaCa}_{4} \mathrm{Si}_{16} \mathrm{O}_{36}(\mathrm{OH}) \cdot 10\left(\mathrm{H}_{2} \mathrm{O}\right)$ was produced, which is considered to be the result of the formation of $\mathrm{Ca}$ and $\mathrm{SiO}_{2}$ in $(\mathrm{Ba})$ and cement [16].

As the peak of the macdonaldite becomes higher, the ettringite and $\mathrm{Ca}(\mathrm{OH})_{2}$ and $\mathrm{C}-\mathrm{S}-\mathrm{H}$ gel peaks gradually become lower. It is thought that the $\mathrm{Si}^{4+}$ and $\mathrm{OH}$ ions that are eluted by the hydration reaction are used to form macdonaldite, and the amount of macdonaldite is expected to increase when the amount of Ba is increased.

\subsection{Scanning Electron Microscopy Analysis}

Figures 5 and 6 present the SEM analysis results. For the OPC mortar, the ettringite and $\mathrm{Ca}(\mathrm{OH})_{2}$ and $\mathrm{C}-\mathrm{S}-\mathrm{H}$ gels increased with aging, and the microstructure and texture of the OPC mortar became more complex on the 28 th day of aging. Figure $5 \mathrm{~d}$ presents the phase transition process in which $\mathrm{Ba}$ is dissolved from a solid to a liquid. As a result, Ba spreads radially as a thread throughout the entire structure and appears to be a complex form together with the other hydrates in the mortar. The SEM analysis also confirmed the macdonaldite measured by XRD analysis. Macdonaldite exhibits longer and thicker nuclei of crystals in PCM-Ba (5\%) than in PCM-Ba (3\%) as well as more crystals in PCM-Ba $(5 \%)$ than PCM-Ba (3\%). Figure $5 \mathrm{~g}$ illustrates the process in which $\mathrm{Sr}$ is phase-transformed. Sr differs from $\mathrm{Ba}$ in that it is mixed in the hydrate of the cement, not in the form of a thread, and spreads widely. As Sr ages, it becomes complex with the other hydrates in the mortar, such as Ba $[17,18]$.

Figure 6 shows the various hydrates in the PCM-added formulations. In the XRD analysis, PCM-Ba and PCM-Sr show a decrease in the peak of the ettringite, unlike the OPC. In the SEM analysis, the ettringite in the mortar that contains PCM is small and a single crystal, unlike the ettringite in the mortar in the OPC that is elongated in shape. The generated Ettringite depends on the amount of $\mathrm{SO}_{4}{ }^{2-}$ ion in the cement matrix. When PCM is added, the $\mathrm{SO}_{4}{ }^{2-}$ ion is combined with $\mathrm{Ba}$ and $\mathrm{Sr}$ to form BaSo4, $\mathrm{SrSo}_{4}$, and other hydrates. It is believed that the production of Ettringite in mortar that contains PCM decreases due to the relatively small amount of $\mathrm{SO}_{4}{ }^{2-}[19,20]$.

\subsection{Flow Analysis}

Figure 7 shows the results of the fluidity evaluation of the cement mortars that contain PCM-Ba and PCM-Sr according to the mix ratio. The flow values are expressed as the average of four-way measurements. The flowability test result for the OPC mortar without PCM is $166.18 \mathrm{~mm}$. In the case of PCM-Ba, the workability decreased by $8.7 \%$ $9.8 \%$ depending on the mix ratio and decreased up to $22 \%$ when PCM-Sr was used. This outcome is thought to be due to the characteristics of Sr and the viscosity of powder, which is more reactive to water than Ba. In the case of PCM-Ba at the same mix ratio, PCM-Ba has greater workability than PCM-Sr. When using PCM-Sr, an appropriate superplasticizer should be used. 


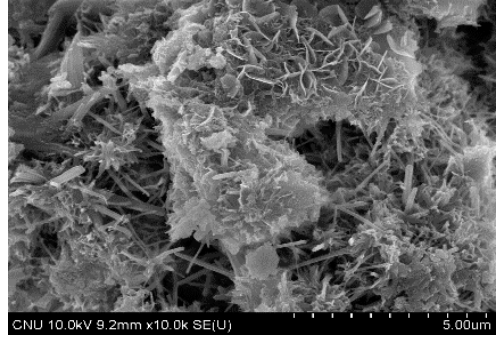

(a)

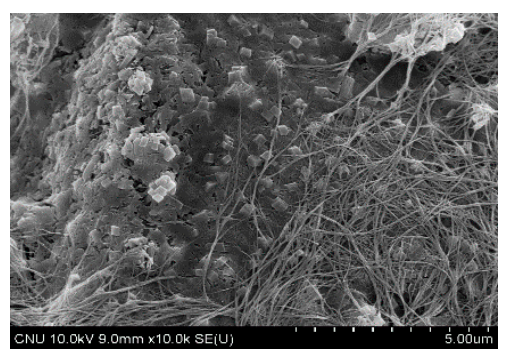

(d)

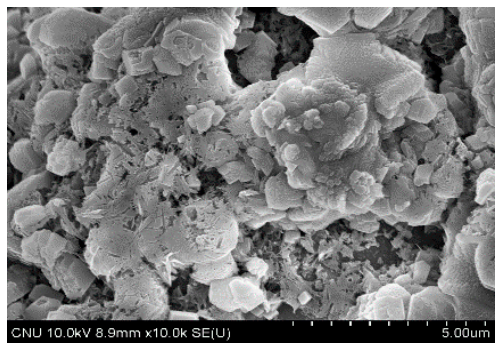

(g)

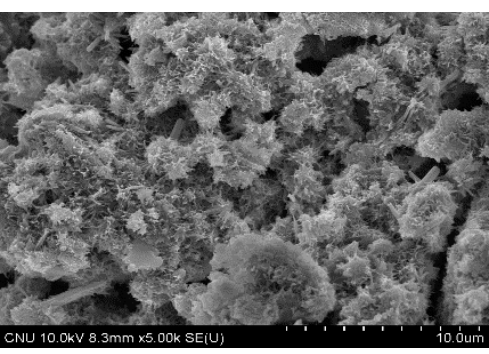

(b)

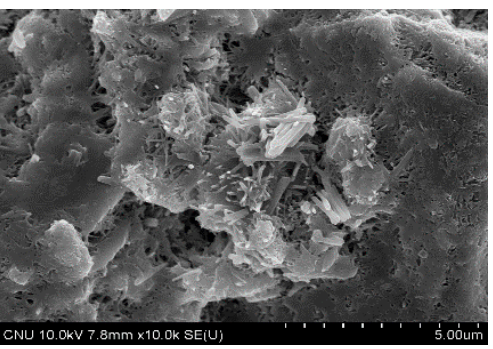

(e)

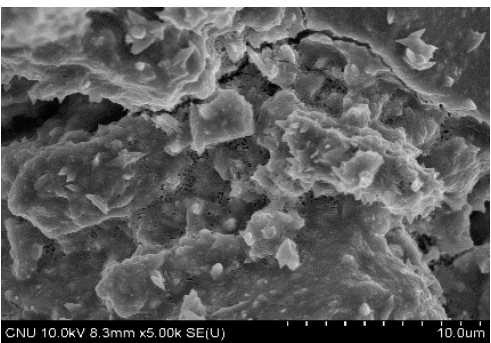

(h)

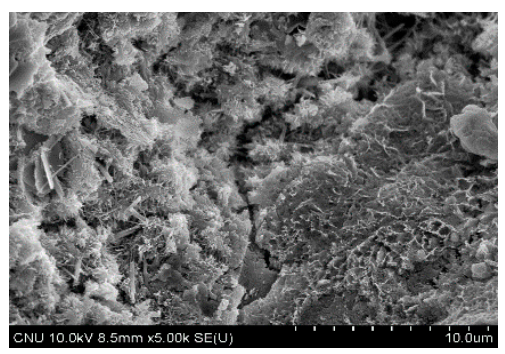

(c)

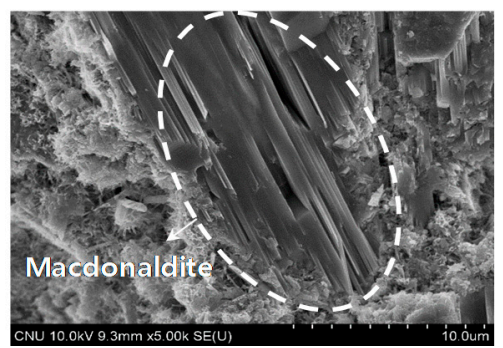

(f)

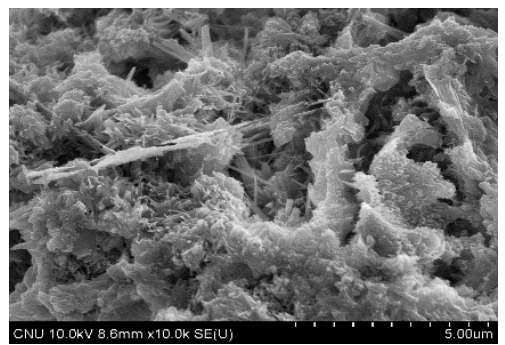

(i)

Figure 5. SEM analysis results of cement mortar for curing time (days)-(a) OPC, 1 day; (b) OPC, 7 days; (c) OPC, 28 days; (d) PCM-Ba, 1 day; (e) PCM-Ba, 7 days; (f) PCM-Ba, 28 days; (g) PCM-Sr, 1 day; (h) PCM-Sr, 7 days; (i) PCM-Sr, 28 days.

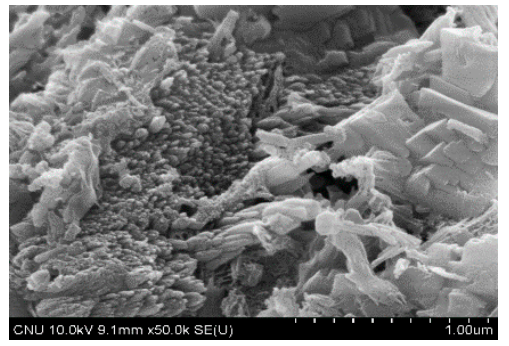

(a)

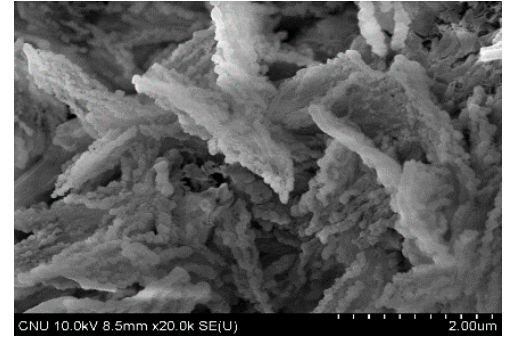

(b)

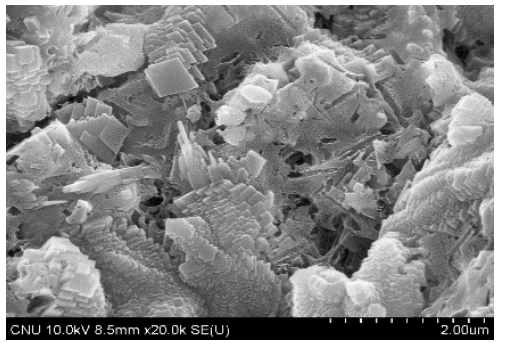

(c)

Figure 6. SEM analysis results for barium oxide and strontium oxide-(a) Sr-oxide; (b) Ba-oxide; and (c) Ba-oxide. 


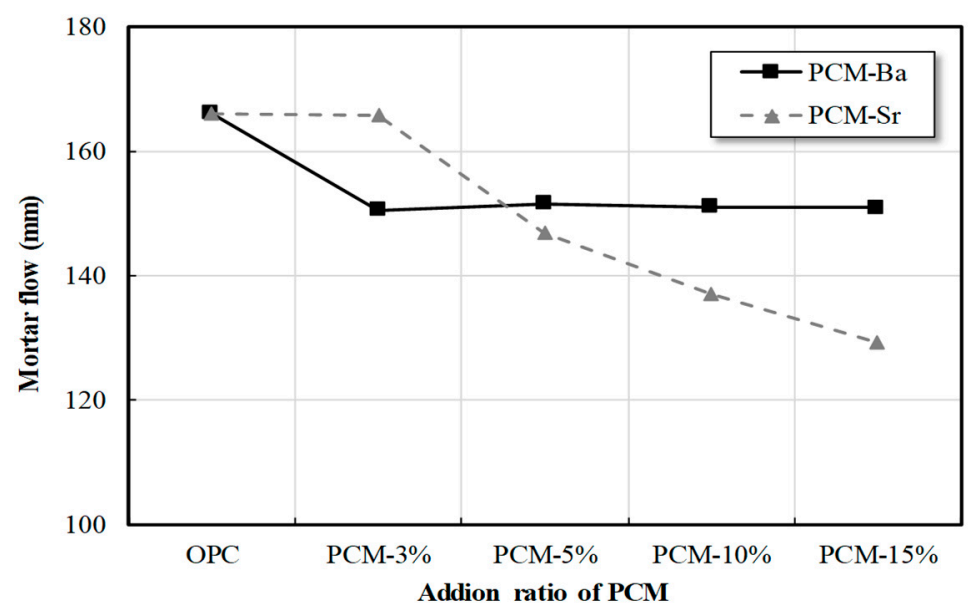

Figure 7. Effects of addition mix ratio of PCM on cement mortar flow.

\subsection{Mechanical Properties}

Figure 8 shows the change in flexural strength according to PCM type and mix ratio and summarizes the test results for up to 91 days of aging. The overall bending strength decreased as the PCM content increased.

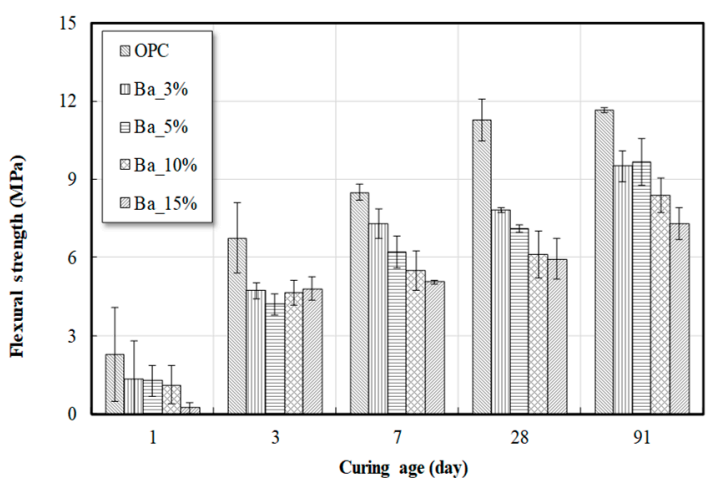

(a)



(b)

Figure 8. Effects of addition mix ratio of PCM on flexural strength-(a) cement mortar with PCM-Ba; (b) cement mortar with PCM-Sr.

Figure 9 shows the changes in compressive strength up to 91 days of aging according to PCM type and mix percentage. Overall, the compressive strength decreases with an increase in PCM content. As seen in Figure 5, PCM-Ba and PCM-Sr are dispersed in the hardened mortar matrix which disturbs the hydration of cement mortar. Moreover, the Mcdonaldite is not the hydration compound. Therefore, mechanical properties such as flexural strength and compressive strength were influenced negatively.

At one day of aging, the compressive strength decreased for the specimens with $12.6 \%$ to $26.6 \%$ PCM-Ba and for specimens with $26 \%$ to $28.7 \%$ PCM-Sr. At three days of aging, the compressive strength decreased continuously with aging. The compressive strength of specimens with PCM-Ba decreased more obviously compared to that of the specimens with PCM-Sr with an increase in the mixing ratio. At seven days of aging, a similar tendency can be observed. Confirmation of the compressive strength is required for mixtures with over 5\% PCM-Ba and over 10\% PCM-Sr. At 28 days and 91 days of aging, the compressive strength is shown to decease regardless of the type of PCM. 


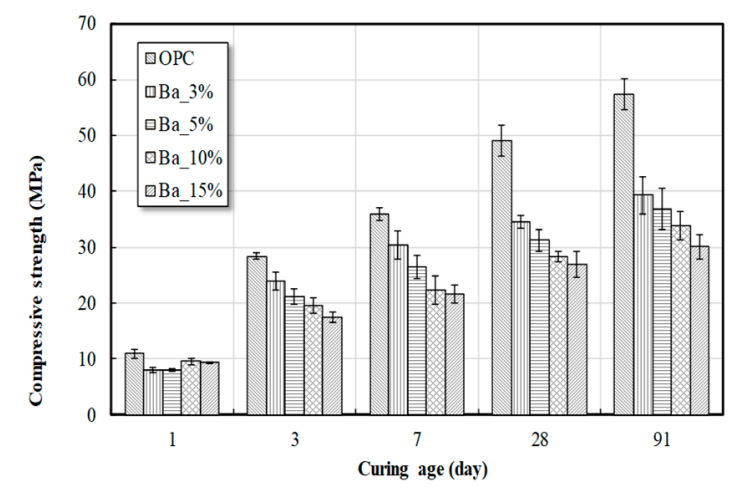

(a)

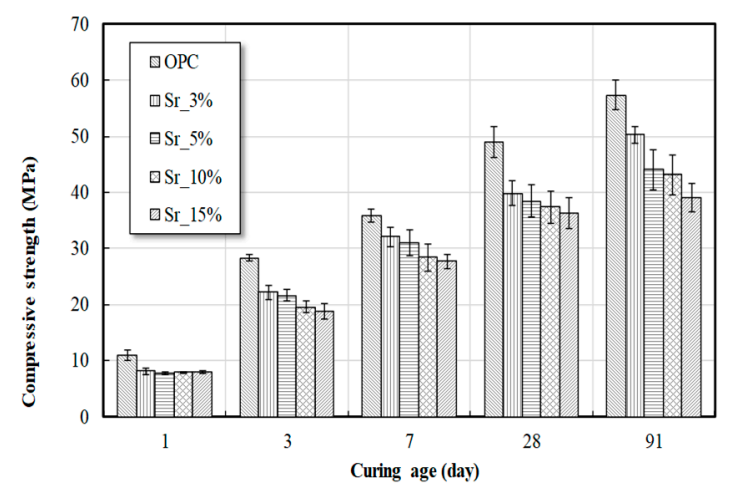

(b)

Figure 9. Effects of addition mixing ratio of PCM on compressive strength-(a) PCM-Ba; (b) PCM-Sr.

\subsection{Semi-Adiabatic Temperature Rise Test}

Figure 10 shows the history of the simple adiabatic temperature rise that is due to the mixing ratios of the OPC and PCMs. Figure 10a shows the experimental results for the cement mortar with PCM-Ba. As the PCM content increased by $3 \% \sim 5 \%$, the maximum hydration heat generation point was induced and the maximum temperature rise decreased. However, when 10\% 15\% PCM-Ba is mixed in, the PCM-Ba shows a similar tendency to the OPC and only the maximum temperature decreased. Figure $10 \mathrm{~b}$ shows the temperature history of the cement mortar with PCM-Sr. For the PCM-Sr mixtures, the hydration heating rate decreased and the maximum hydration heat generation point decreased more obviously compared with the OPC. Specifically, the maximum hydration heat rate is slower than $3 \%$ at the mix ratio of $5 \%$ to $15 \%$. This outcome indicates that the added PCM-Sr is not consumed. In the case of PCM-Sr, more than 3\% addition is not likely to have a significant effect in reducing the hydration heat.

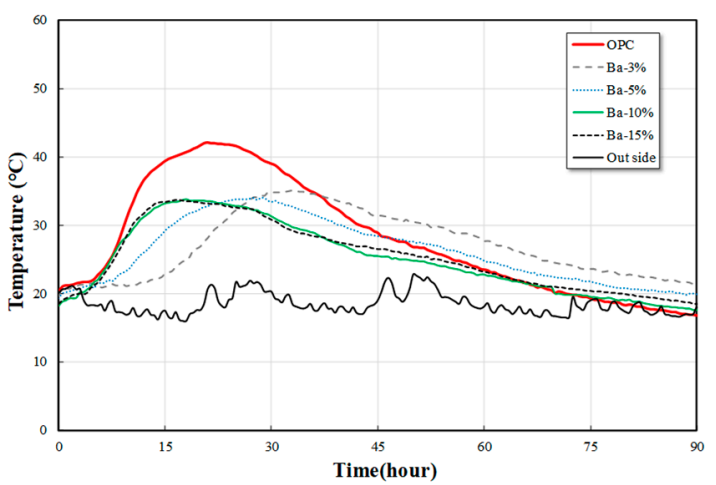

(a)



(b)

Figure 10. Effects of addition mix ratio of PCM on semi-adiabatic temperature rise-(a) cement mortar with PCM-Ba; (b) cement mortar with PCM-Sr.

Figure 11 shows the maximum temperature rise and development time according to the type of PCM and mixing percentage. The hydration heat reduction effect is $16.6 \%$ at the mix ratio of $3 \%$ PCM-Ba. As the mixing percentage increases, the hydration heat reduction percentages of $19.2 \%$, $19.7 \%$, and $20 \%$ are evident at mixing percentages of $5 \%, 10 \%$, and $15 \%$, respectively. The maximum temperature rise is shown to decrease according to the amount of the mixture with PCM-Ba, but the difference of maximum temperature rise is negligible. Therefore, the effective mix percentage for hydration heat reduction is less than 5\% addition of PCM-Ba.

The maximal temperature development time for 3\% and 5\% PCM-Ba shows hydration delays of 1.57 and 1.36 times, respectively, whereas the maximum temperature development times for the 
mixing ratios of $10 \%$ and $15 \%$ show hydration delays of 0.86 and 0.79 , respectively, which are faster results than for OPC. Therefore, the effective mixing rate for hydration heat reduction is less than $5 \%$ addition of PCM-Sr, which is based on the results of the maximum temperature rise tests and development time.

When PCM-Sr is used, the mixing ratios of $3 \%, 5 \%, 10 \%$, and $15 \%$ are reduced by $23.7 \%, 20 \%$, $20.2 \%$, and $21.5 \%$, respectively, resulting in a higher hydration heat reduction rate compared to PCM-Br. However, unlike PCM-Ba, which shows a sequential decrease in hydration heat as the mixing percentage increases, $5 \%$ to $15 \%$ excluding 3\% PCM-Sr decreases the reduction in hydration heat.

When PCM-Sr is used, the maximum temperature expression time shows sequential hydration delays up to 1.6 times from the mix percentages of $3 \%$ to $15 \%$. When the mix ratio is over $10 \%$, the difference in delaying effects is insignificant. Therefore, considering the maximum temperature rise and the expression time, the effective mix ratio of PCM-Sr to reduce hydration heat is to be up to $3 \%$. In short, the use of PCM-Ba is effective in reducing hydration heat and the use of PCM-Sr is effective in delaying hydration.



Figure 11. Effects of addition mix ratio of PCM on hydration heat properties.

\section{Conclusions}

This study was conducted to evaluate the microstructure and mechanical properties of cement mortar according to the type and percentage of the PCM added to the mix. To this end, we evaluated the feasible amount of PCM-Ba and PCM-Sr when mixed into cement mortar with mix ratios of $0 \%$ to $15 \%$. The conclusions drawn from this study for limited laboratories are as follows:

(1) The microstructural analysis results show that the crystalloid content of cement mortar without PCM differs by about 3\% from the crystalloid content of cement mortar with PCM regardless of the type of PCM used, and not much difference is evident in the formation of crystals between cement mortar with and without PCM. PCM-Ba and PCM-Sr were found to act on the hydration reactions within the cement matrix, generating oxides of Ba-oxide and Sr-oxide in addition to hydration compounds. Also, we found that the cement paste containing Br produced macdonaldite $\left(\mathrm{BaCA}_{4} \mathrm{Si}_{16} \mathrm{O}_{36}(\mathrm{OH})_{2} \bullet 10\left(\mathrm{H}_{2} \mathrm{O}\right)\right)$.

(2) PCM mix ratios of $3 \%$ to $15 \%$ do not have much effect on flexibility. We also found that the use of PCM-Sr decreases the workability compared to the PCM-Ba at the same mix percentage.

(3) As the PCM addition rate increases, the bending strength decreases. Although the strength of the bending increases due to the increase in aging, PCM-Ba does not perform well in terms of flexural strength, even in the long term, so PCM-Sr is favorable for the performance in flexure. 
(4) The compressive strength evaluation shows a decrease in compressive strength due to the mixing of PCM into cement mortar, and the decrease in initial strength is significant. In addition, PCM-Ba showed a more rapid drop in compressive strength compared to PCM-Sr. Therefore, it is assumed that the application of PCM-Ba will require user review.

(5) The test results show that the temperature increase and maximum temperature release time of PCMs were delayed up to $5 \%$ of the mixing ratio. Both PCM-Ba and PCM-Sr are effective in reducing hydration heat development.

Author Contributions: H.-D.Y. and Y.-I.J. contributed to the project idea development and experimental design, and J.-W.L. and S.-J.J. performed the experiment and data analysis. W.C. reviewed the final manuscript and contributed to the results, discussion, and conclusions.

Funding: This research was funded by the Gachon University research fund of 2018 (GCU-2018-0317). Also this work has supported by the National Research Foundation of Korea (NRF) grant funded by the Korea government (MSIT) (No. NRF-2017R1D1A1B03028748).

Conflicts of Interest: The authors declare that there is no conflict of interests regarding the publication of this article.

\section{References}

1. Coppola, L.; Coffetti, D.; Crotti, E. Plain and ultrafine fly ashes mortars for environmentally friendly construction materials. Sustainability 2018, 10, 874. [CrossRef]

2. Coppola, L.; Lorenzi, S.; Kara, P.; Garlati, S. Performance and compatibility of phosphonate-based superplasticizers for concrete. Buildings 2017, 7, 62. [CrossRef]

3. Wang, X.Y.; Lee, H.S. Modeling the hydration of concrete incorporating fly ash or slag. Cem. Concr. Res. 2010, 40, 984-996. [CrossRef]

4. Kim, J.K.; Kim, K.H.; Yang, J.K. Thermal analysis of hydration heat in concrete structures with pipe-cooling system. Comput. Struct. 2001, 79, 163-171. [CrossRef]

5. Patil, A. Heat of Hydration in the Placement of Mass Concrete. IJEAT 2015, 4, 1-4.

6. Gajda, J.; Vangeem, M. Controlling Temperatures in Mass Concrete. Concr. Int. 2002, 24, 58-62.

7. Schackow, A.; Effting, C.; Gomes, I.R.; Patruni, I.Z.; Vicenzi, F.; Kramel, C. Temperature variation in concrete samples due to cement hydration. Appl. Therm. Eng. 2016, 103, 1362-1369. [CrossRef]

8. Ling, T.C.; Poon, C.S. Use of phase change materials for thermal energy storage in concrete: An overview. Constr. Build. Mater. 2013, 46, 55-62. [CrossRef]

9. Speyer, R.F. Thermal Analysis of Materials; CRC Press: Boca Raton, FL, USA, 1994; ISBN 0824789636.

10. Levermore, G.J. A review of the IPCC Assessment Report Four, Part 1: The IPCC process and greenhouse gas emission trends from buildings worldwide. Build. Serv. Eng. Res. Technol. 2008, 29, 349-361. [CrossRef]

11. Kim, Y.R.; Kim, D.S.; Khil, B.S.; Kim, O.J.; Lee, D.B. An Experimental on Properties of Concrete Using Latent Heat Binder. J. Korea Concr. Inst. 2008, 20, 661-668.

12. Zhang, D.; Li, Z.; Zhou, J.; Wu, K. Development of thermal energy storage concrete. Cem. Concr. Res. 2004, 34, 927-934. [CrossRef]

13. Zalba, B.; Marín, J.M.; Cabeza, L.F.; Mehling, H. Review on thermal energy storage with phase change: Materials, heat transfer analysis and applications. Appl. Therm. Eng. 2003, 23, 251-283. [CrossRef]

14. ASTM International. ASTM C1437-15 Standard Test Method for Flow of Hydraulic Cement Mortar; ASTM International: West Conshohocken, PA, USA, 2015. [CrossRef]

15. Korean Standards Association. KS L ISO 679: Methods of Testing Cements-Determination of Strength; Korea Industrial Standards; Korea Standards Association: Seoul, Korea, 2006.

16. Kampf, A.R.; Housley, R.M.; Dunning, G.E.; Walstrom, R.E. Esquireite, $\mathrm{BaSi}_{6} \mathrm{O}_{13}-7 \mathrm{H}_{2} \mathrm{O}$, a new layer silicate from the barium silicate deposits of California. Can. Mineral. 2015, 53, 3-12. [CrossRef]

17. Sanoguera, D.G.; Varón, D.J.; Gimeno, R.A.B.; Bou, S.F. Estudio de materiales con cambio de fase (PCM) y análisis SEM de micro PCM. 3C Tecnol. 2012, 1, 4.

18. Schmidmair, D.; Kahlenberg, V.; Praxmarer, A.; Perfler, L.; Mair, P. Investigations on the crystal-structure and non-ambient behaviour of $\mathrm{K}_{2} \mathrm{Ca}_{2} \mathrm{Si}_{8} \mathrm{O}_{19}-\mathrm{A}$ new potassium calcium silicate. J. Solid State Chem. 2017, 253, 336-346. [CrossRef] 
19. Cao, V.D.; Pilehvar, S.; Salas-Bringas, C.; Szczotok, A.M.; Rodriguez, J.F.; Carmona, M.; Al-Manasir, N.; Kjøniksen, A.L. Microencapsulated phase change materials for enhancing the thermal performance of Portland cement concrete and geopolymer concrete for passive building applications. Energy Convers. Manag. 2017, 133, 56-66. [CrossRef]

20. Suttaphakdee, P.; Dulsang, N.; Lorwanishpaisarn, N.; Kasemsiri, P.; Posi, P.; Chindaprasirt, P. Optimizing mix proportion and properties of lightweight concrete incorporated phase change material paraffin/recycled concrete block composite. Constr. Build. Mater. 2016, 127, 475-483. [CrossRef]

(C) 2019 by the authors. Licensee MDPI, Basel, Switzerland. This article is an open access article distributed under the terms and conditions of the Creative Commons Attribution (CC BY) license (http:/ / creativecommons.org/licenses/by/4.0/). 